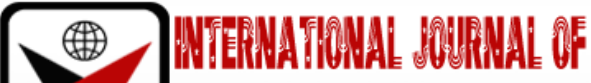

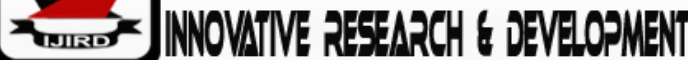

ISSN 2278-0211 (Online)

\section{An Analysis of Automobile Hydrocarcbon (HC) Emission Level in Lagos State, Nigeria}

\author{
Osita Stanley Onyemelukwe \\ Lecturer, Transport School \\ Nigeria Institute of Transport Technology Zaria, Kaduna State, Nigeria \\ Garba, A.H. \\ Lecturer, Department of Geography, \\ Taraba State University, Jalingo Taraba State, Nigeria \\ Ibrahim, K.Z. \\ Lecturer, Department of Environmental Science, Kaduna State Polytechnic, \\ College of Environmental Science, Kaduna State, Nigeria
}

\begin{abstract}
:
Automobile emission is considered as one of the major sources of atmospheric hydrocarbon. Due to its distinctive abilities to interact individually or in aggregate with other pollutants, hydrocarbon emission compromises air quality thus a major contributor to smog in many large cities of the world as well as the deteriorating health issues such as asthma, liver disease, lung disease and cancer. Thus study is focused on the analysis of automobile hydrocarbon emission levels in Lagos State, Nigeria. The automobile emission levels of hydrocarbon pollutant data was generated from sampling 312 different types of automobiles using Testo 350XL emission sensor. The result showed that the emission levels of hydrocarbon from the categories of automobiles sampled were found to be above the standards set by LASEPA/EURO III, with tricycle and motorcycle recording over 100\% higher level of hydrocarbon emission of 4808.5ppm and 3079.43ppm compared to the LASEPA/EURO III set standard of 35.03ppm. The results also showed that petrol vehicles are the highest emitter of hydrocarbon pollutant with an average estimated level of 997.92ppm, whereas, the concentration from diesel engines accounted for 779.23ppm. Single time factor analysis of variance (ANOVA) results shows that emission concentration of hydrocarbon pollutants from the sampled automobiles differs significantly across different categories of automobiles. This is shown where the mean difference in hydrocarbon pollutant concentration between different automobiles reveals F30.429 at 0.000. Therefore, given the finding from this study, it is pertinent for the regulatory authorities (LASEPA and Vehicle Inspection Service) to strictly mandate and ensure that as a part of road worthiness requirements for vehicles operated in the State, every vehicles operating in the State must be subjected to a periodic emission test on a 6 months and 1 year durations for commercial and private vehicles respectively. As this will go a long way in reducing the concentration of this dangerous pollutant released into the air which will invariably reduce the impacts on human health and environment.
\end{abstract}

Keywords: Emission concentration, automobile, hydrocarbon, pollutant, Lagos

\section{Introduction}

Emission of gaseous pollutants into the atmosphere has been shown to constitute significant negative effects to public health and the natural environment. In many urban centres across the world, human activities which lead to poor or deteriorating air quality are on the increase. For instance, United State Environmental Protection Agency (USEPA) (1994); as well as Awange (2010) unanimously identified automobile emission as a key factor in the deterioration of urban environment, constituting up to $80-90 \%$ of pollutants emitted into the atmosphere particularly in the city centres of most developing countries. Among these dangerous pollutants emitted into the atmosphere is Hydrocarbon (HC) which is a class of burned and partially burned fuel resulting from the internal combustion of engines (Wallington, Sullivan, and Hurley, 2008). Hydrocarbon is a pollutant consisting of carbon and hydrogen atoms with distinctive abilities to interact individually or in aggregate with other pollutants to affect air quality thus a major contributor to smog in many large cities of the world (Sprawl, 2001). Prolonged exposure to hydrocarbon contributes to asthma, liver disease, lung disease and cancer (Wargo, Wargo, Aiderman and Brown, 2006).

Notably, of more concern to environmentalists, transport developers and urban planners among other experts is the fact that despite the dangers posed by automobile emission to the environment and health of organisms. The emission levels of these dangerous gases are expected to increase reasonably especially in developing countries due to increased vehicular ownership attributable to improvement in living standards, poor vehicle maintenance culture, weak regulations 
of automobile emission and high importation of used vehicles popularly called 'Tokumbo vehicles', which is also called super emitters. As noted by Brunekeef (2005) in developing countries, the super emitters (which in Nigeria parlance are called Tokumbo vehicles) contribute about $50 \%$ of harmful emissions to the entire total emission.

In addition to the foregoing highlighted factors, it is estimated that over 1 million vehicles ply the roads across the State on daily basis, with a record vehicular density of over 222 vehicles/km compared to the country's average of $11 / \mathrm{km}$. It therefore will not be surprising to witness increased traffic congestion which makes the State more vulnerable to higher traffic related hydrocarbon emission. In concurrence to the above, Bull (1991; Barth and Boriboonsomsin, (2008) observed that due to congestion and traffic hold ups, vehicles in idling condition produce higher average concentrations of pollutants faster than the actual growth in the number of vehicles. For most of the studies available, focusing on emission of hydrocarbons is rarely given deserving research attention which has created a gap in knowledge. This gap is what this paper addresses in Lagos state owing to increasing vehicular and human population in the study area.

Given the above, it is pertinent to carry out this study with focus on the emission level of hydrocarbon pollutant. It is expected that the finding will serves as pointers to policy makers on the need to formulate a legislative framework or standard on automobile pollutant emission beyond the Lagos State to other States in the country in general, especially considering the fact that the regulatory framework put in place in 1991 by the Federal government through the then Federal Environmental Protection Agency (FEPA), currently known as NESREA is limited to emission generated through stationary sources. This is because, although, more emission may take place in a particular region of the world, the climate change impacts on the long run are felt globally. Hence greenhouse gas emission impacts on the climate of the environment are therefore not restricted to where it is being emitted but the effect is global (U.S. Global Change Research Program, 2005).

This study therefore analyses the emission levels of hydrocarbon (HC) from automobiles in Lagos State Nigeria. The specific objectives achieved; are analysis of hydrocarbon emission levels of different categories of sampled automobiles in the study area, ascertain the hydrocarbon emission levels of different brands of sampled automobiles in the study area and compare the emission level of hydrocarbon pollutant from the sampled automobiles with the LASEPA/EURO III standard.

\section{Study Area}

Lagos State is located in the south-western part of Nigeria. It lies within latitudes $6^{\circ} 20^{\prime} \mathrm{N}$ and $6^{\circ} 40^{\prime} \mathrm{N}$ and longitude $2^{\circ} 40^{\prime} \mathrm{E}$ and $4^{\prime} 20^{\prime} \mathrm{E}$. The state shares boundaries with Benin Republic to the west, Ogun State to the north and east and Bright of Benin of the Atlantic Ocean to the south. It has a land area of about 3,577.28sq.km out of which $22 \%$ is occupied by water (Lagos State Ministry of Land and Survey, 2013). The state occupies a pre-eminent position socioeconomically and based on all urban indicators, most especially demography with a total population of $17,552,942$ (National Population Commission (NPC) (2009).

The state has a population density of about 2,400 persons $/ \mathrm{km}^{2}$ with annual population growth rate of between 5.0 to $5.5 \%$ (Taiwo, 2005). It is known to occupy an enviable position as the most commercial, industrial and trading activities centre in Nigeria compared to other states and generates about 25\% of Nigeria's gross domestic products World Population Review (WPR) (2015). The state has well developed inter-modal transport infrastructural facilities; with road transport dominating more than 90 percent of all intra -urban movement (Oni, 2004); as well as having the highest national vehicular density of over 222 vehicles/km against country average of $11 / \mathrm{km}$ with a resultant impact on high incidence of air and noise pollution.

\section{Materials and Methods}

A reconnaissance survey was carried out, during which consultations were made with relevant personnel and agencies responsible for environmental regulations and traffic management such as Lagos State Environmental Protection Agency (LASEPA) and Lagos State Traffic Management Authority (LASTMA) for updates on environmental and traffic related issues, as well as a visit to the State Chapter of FRSC (Vehicle Inspection Service Unit) to their support and assistance in the data collection processes.

The methodology is hinged on experimental design where captive techniques are used for data collection. Exhaust emission study required extensive planning, preparations and coordination with traffic officials and security agencies. The first step was to understand the fleet of automobile types, models, maker/manufacturer, fuel use types, vehicular size and weight as well as an understanding of the operational modes of the various types of automobiles of interest. The data collection procedures employed includes the following:

- Instrumentation: This involved the measuring of exhaust emission of Hydrocarbon level using a standard Testo 350XL gas sensor. The instrument was setup to provide emission analysis output on a 1-second interval. In order to facilitate efficient data logging, the instrument was connected to the computer and data download was performed on a real-time basis.

- Automobile Selection and Sampling Process: A systematic random sampling technique was used to gather the pollutant emission data from sampled automobile. In order to collect maximum data within a short span of time, avoid the obstruction of traffic flow and ensure reasonable compliance of drivers, the Lagos State vehicle inspection officers were involved in the process of data collection.

- Exhaust pipe attachment: This process involved the insertion of Testo 350 XL sensor pipe into the vehicular exhaust which is usually wide enough to allow the probes to pass through while the vehicle was on idle mode. Thereafter the reading was recorded and downloaded into the computer system. 
- $\quad$ Exhaust pipe Testing Procedures: The emission data was collected from selected vehicles on idling mode which is connected to an emission analyser pipe which is attached to a computer from where the reading is displayed. Thereafter, the analysed pollutant is then generated and prepared for data logging. Emission monitoring instrumentation was connected to the sampling probes that were setup at the tailpipe/exhaust. Both sets of instruments were started simultaneously for easy comparison of the data. The automobile was then started in the desired idling mode (fast or normal idle) and the emission characteristics were monitored for at least 3-5 minutes.Table 1 below shows the actual number and types of automobiles sampled in the study.

\begin{tabular}{|c|c|}
\hline Automobiles Types & Sampled Number \\
\hline Car & 140 \\
\hline Trucks & 2 \\
\hline Mini Bus & 140 \\
\hline Omni bus & 12 \\
\hline Motorcycle & 14 \\
\hline Tri-cycle & 4 \\
\hline
\end{tabular}

Table 1: Number and Types of Automobiles Sampled

Source: Field Compilation

\section{Results and Discussions}

Figure 1 shows the concentration of hydrocarbon pollutant emitted from various categories of automobiles. From the presentation, it reveals that the emission levels of hydrocarbon from the categories of automobiles sampled were found to be above the standards set by LASEPA/EURO III.

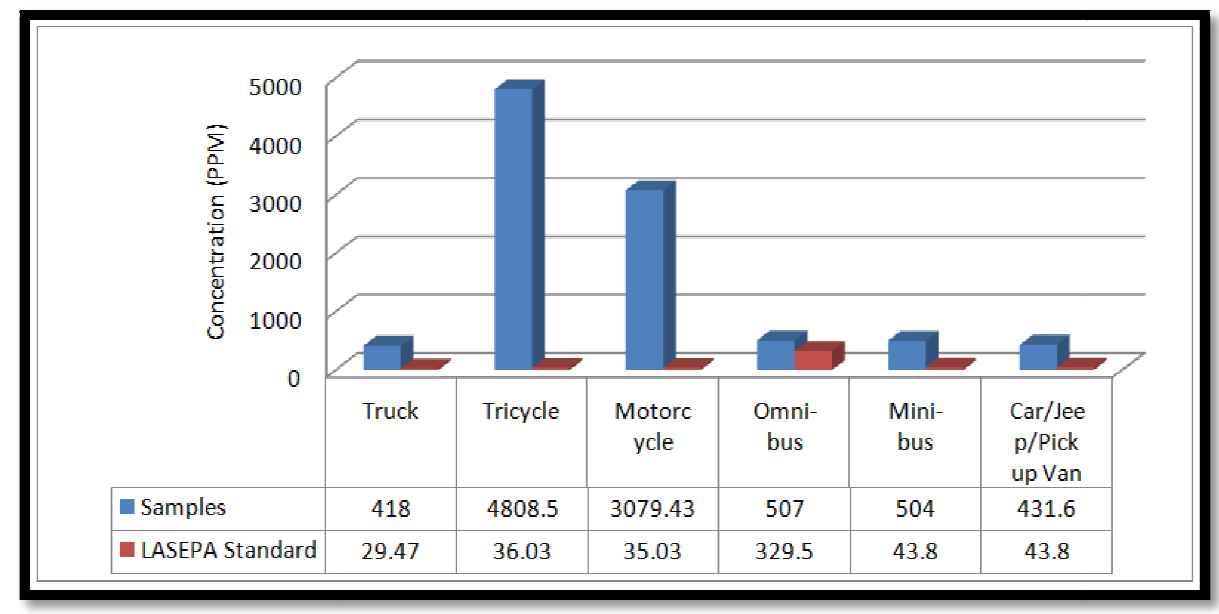

Figure 1: Hydrocarbon Emission Levels of Different Categories of Sampled Automobiles Source: Field Survey (2017)

Also, it shows that tricycle and motorcycle have over $100 \%$ higher level of hydrocarbon emission of $4808.5 \mathrm{ppm}$ and 3079.43ppm compared to the LASEPA/EURO III set standard of 35.03ppm. This finding can be justified with a study by Hesterberg, Lapin and Bunn (2008) where it was reported that auto-rickshaws (Tricycles) 2-strokes (motorcycles) and un-maintained vehicles are great contributors of HCs, non-methane HC, and carbonyl compounds as compared to 4-stroke engines.

It is observed from Figure 2 that Jincheng and NIPON brands of motorcycles emit the highest quantity of HCs of 9520ppm and 8781ppm respectively. This is followed by tricycle brands of Bajeng 3709.4ppm and NIPON 4420ppm. This high concentration of HC released into the air from this class of automobile is quite worrisome because they are not only the most widely used medium of transport in the city due to their manoeuvrability compared to other mediums of transport, they can be more injurious to humans through negative health effects as well as contribute to the ground-level ozone concentration or smog, if left unchecked.

In addition, Chevrolet car was found to emit the least level of hydrocarbon pollutant, whereas, heavy duty automobile brands such as Marcopolo omnibus, Mark and Man Diesel brands of trucks were found to emit 510.95ppm, 465ppm and 3707ppm of hydrocarbon pollutant, compared to light engine or 2 stroke engines. This finding is expected because diesel and large engine automobiles are known to emit mostly NO pollutants than petrol engines due to the engine and fuel characteristics of such automobiles. This view has been substantiated in the submission by European Automobile Manufacturers Association/European Petroleum Industry Association (1995) that different fuel composition and characteristics play an important role in engine design and emissions performance, although the relationships among fuel properties, engine technologies and exhaust emissions are complex, but changes in one fuel characteristic may lower emissions of one certain pollutant and may increase those of another (for example, decreasing aromatics content in petrol lowers $\mathrm{CO}$ and $\mathrm{HC}$ emissions but increases NOx emissions). 


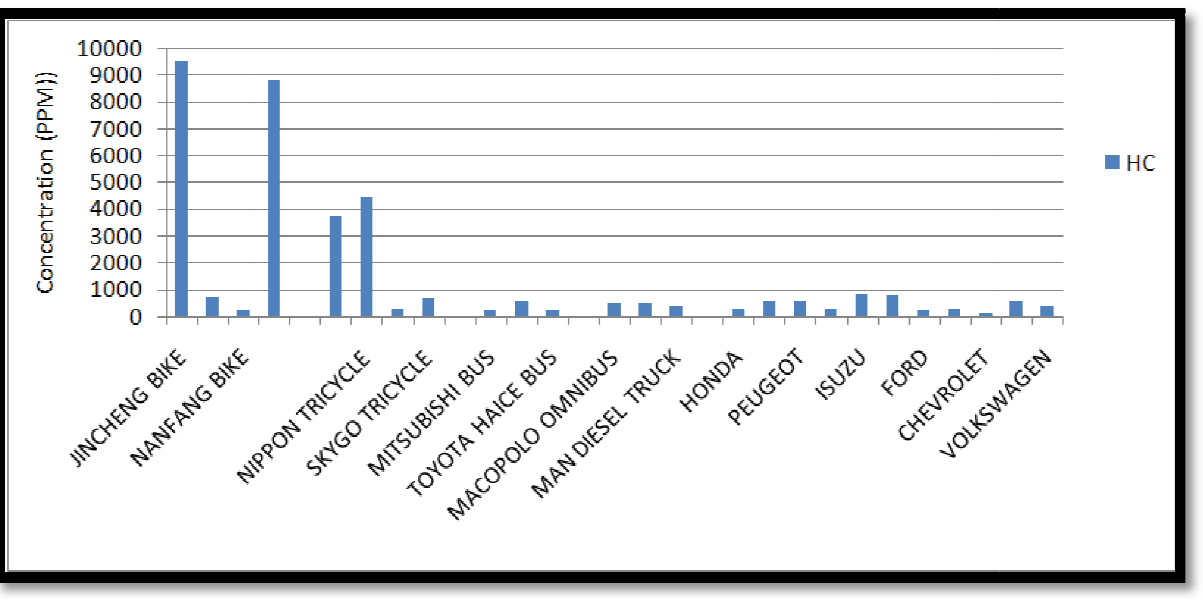

Figure 2: Hydrocarbon Emission Levels of Different Brands of Sampled Automobiles Source: Field Survey (2017)

Figure 3 shows the levels of hydrocarbon pollutant emitted from diesel and petrol engine automobiles sampled in the study. The presentation shows that petrol vehicles are the highest emitter of Hydrocarbon pollutant with an average estimated level of $997.92 \mathrm{ppm}$, whereas, the concentration from diesel engines accounted for 779.23ppm.

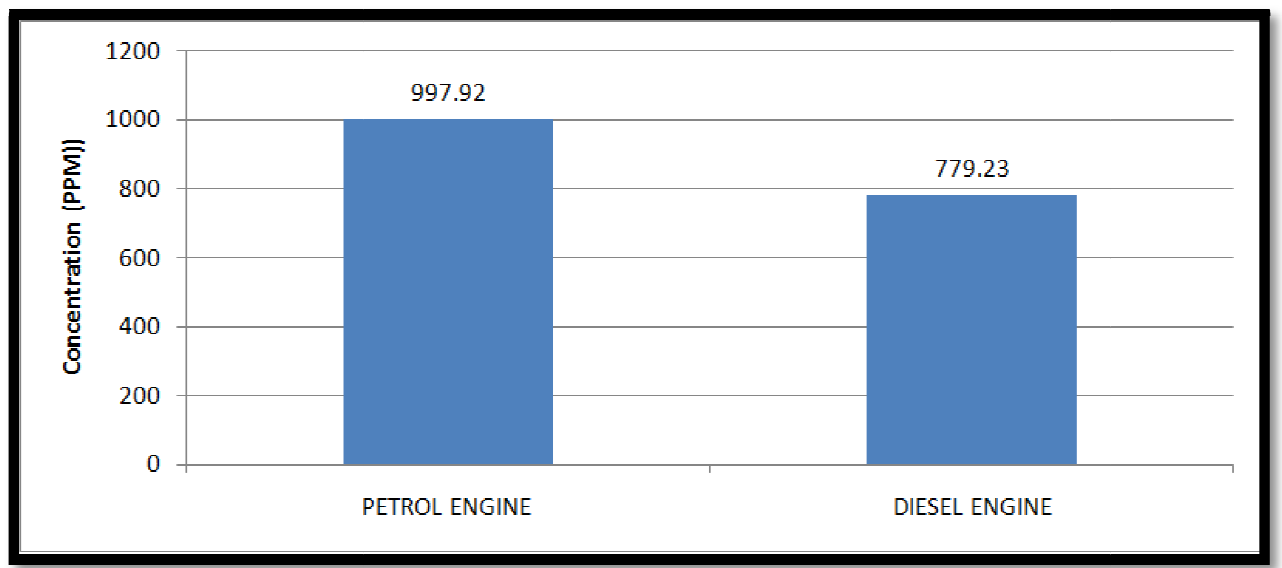

Figure 3: Hydrocarbon Emission Differentials from Diesel and Petrol Engine Automobiles Source: Field Survey (2017)

The higher concentration of HC pollutant from petrol engine automobiles is attributable to the differentials in the allowable additives during the refining process of both types of fuel. This assertion is justified with the report by Enviropedia (2017) that diesel fuel contains no lead as such; the emissions of regulated pollutants (Hydrocarbons and Nitrogen oxides) are lower than those from petrol cars.

Table 2 is a presentation of test for emission differentials of Hydrocarbon pollutant from various sampled automobiles using single time factor analysis of variance (ANOVA) statistical technique at 0.05 statistically significant levels, the results shows that emission concentration of Hydrocarbon pollutants from the sampled automobiles differs significantly across different categories of automobiles. This is shown where the mean difference in Hydrocarbon pollutant concentration between different automobiles reveals F30.429 at 0.000 .

\begin{tabular}{|c|c|c|c|c|c|c|}
\hline Variables & & Sum of Squares & Df & Mean Square & F & Sig. \\
\hline \multirow{2}{*}{ HC } & Between Groups & $1.616 \mathrm{E} 8$ & 5 & $3.232 \mathrm{E} 7$ & 30.429 & .000 \\
\cline { 2 - 7 } & Within Groups & $3.250 \mathrm{E} 8$ & 306 & 1062023.871 & & \\
\cline { 2 - 7 } & Total & $4.866 \mathrm{E} 8$ & 311 & & & \\
\hline
\end{tabular}

Table 2: ANOVA Result of Hydrocarbon Pollutant Concentrations from Automobiles Source: Field Survey (2017)

This finding is indeed not surprising as this can be attributed to the automobile engine make ups (which could be large, medium or small), fuel composition, and frequency of maintenance of vehicles amongst others.

This finding shares similarity with the study by Guensler, Sperling, and Jovanis (1991)that high levels of NO emissions from heavy-duty vehicles are caused by the characteristics of diesel engines, that is, diesel engines operates at higher combustion chamber pressures and temperatures than gasoline engines, with both conditions conducive for high NO emission levels. As well as the submission by Conte (1990) that emissions of $\mathrm{SO}_{2}$ are substantially higher for diesel than for gasoline engines because of the high sulphur content composition in diesel fuel, whereas, diesel fuel contains no 
lead, unlike the petrol engines therefore emissions of the regulated pollutants (carbon monoxide, hydrocarbons and nitrogen oxides) are lower than those from petroleum cars.

Table 3 shows the mean concentration differentials of hydrocarbon emissions from different sampled automobiles in the study area. The result indicates that there exists strong statistical difference between hydrocarbon emissions in cars, motorcycles and tricycles at 0.05 significant levels, whereas, there is no statistical difference in the emission of the same pollutant between cars and trucks, mini-bus and Omni-buses with p-vales of $1.000, .997$ and 1.000.The finding on the emission of hydrocarbon pollutants between cars, motorcycles and tricycles is unexpected especially in cars. This is because hydrocarbon emissions in two or three stroke engines are caused by misfire or partial combustion at light loads as submitted by Hesterberg, Lapin and Bunn, (2008). However, the reason for the similarity in the emission of hydrocarbon pollutant between cars, motorcycles and tricycles may be connected to the usage of air conditions in cars which increases the engine loads, hence, makes it favourable for higher emission of hydrocarbon pollutant.

Further multiple comparisons of the differentials in Hydrocarbon pollutant emission concentration between trucks and the other sampled types of automobiles also reveal that there exists strong statistical difference between the emission concentration of hydrocarbon pollutant in trucks, motorcycles and tricycles at 0.05 significant levels. Conversely, the emission concentration of Hydrocarbon pollutant in trucks does not differ statistically between cars, mini-buses and omni-buses which show p-vales of 1.000 each.

The comparison of tricycle emission concentration of hydrocarbon pollutant with other types of sampled automobiles in Table 3 also indicates that there exist strong statistical differences between tricycles and cars, trucks, minibuses and omni-buses at 0.05 significant levels, except with motorcycles which show p-value of .123. This finding maybe as a result of partial combustion of petrol powered engines which is usually very common in both motorcycles and tricycles.

\begin{tabular}{|c|c|c|c|c|c|c|}
\hline \multirow{2}{*}{\multicolumn{2}{|c|}{ Automobile Types }} & \multirow{3}{*}{$\begin{array}{c}\begin{array}{c}\text { Mean } \\
\text { Difference }\end{array} \\
16.8137 \\
\end{array}$} & \multirow{3}{*}{$\begin{array}{l}\text { Std. Error } \\
733.8922 \\
\end{array}$} & \multirow{3}{*}{$\begin{array}{l}\text { Sig. } \\
1.000\end{array}$} & \multicolumn{2}{|c|}{ 95\% Confidence Interval } \\
\hline & & & & & \multirow{2}{*}{$\begin{array}{c}\text { L/Bound } \\
-2441.175 \\
\end{array}$} & \multirow{2}{*}{$\begin{array}{l}\text { U/Bound } \\
2474.802\end{array}$} \\
\hline Car & Trucks & & & & & \\
\hline & Mini Bus & -70.2720 & 123.1737 & .997 & -482.812 & 342.268 \\
\hline & Omni-bus & -72.3363 & 309.9804 & 1.000 & -1110.538 & 965.866 \\
\hline & Motorcycle & $-2644.7649^{*}$ & 288.8680 & .000 & -3612.256 & -1677.274 \\
\hline & Tricycle & $-4373.8363^{*}$ & 522.5819 & .000 & -6124.094 & -2623.579 \\
\hline \multirow[t]{5}{*}{ Trucks } & Car & -16.8137 & 733.8922 & 1.000 & -2474.802 & 2441.175 \\
\hline & Mini Bus & -87.0857 & 733.8922 & 1.000 & -2545.074 & 2370.903 \\
\hline & Omni-bus & -89.1500 & 787.0921 & 1.000 & -2725.318 & 2547.018 \\
\hline & Motorcycle & $-2661.5786^{*}$ & 779.0191 & .042 & -5270.708 & -52.449 \\
\hline & Tricycle & $-4390.6500^{*}$ & 892.4785 & .000 & -7379.784 & -1401.516 \\
\hline \multirow[t]{5}{*}{ Mini Bus } & Car & 70.2720 & 123.1737 & .997 & -342.268 & 482.812 \\
\hline & Trucks & 87.0857 & 733.8922 & 1.000 & -2370.903 & 2545.074 \\
\hline & Omni-bus & -2.0643 & 309.9804 & 1.000 & -1040.266 & 1036.138 \\
\hline & Motorcycle & $-2574.4929^{*}$ & 288.8680 & .000 & -3541.984 & -1607.002 \\
\hline & Tricycle & $-4303.5643^{*}$ & 522.5819 & .000 & -6053.822 & -2553.307 \\
\hline \multirow[t]{5}{*}{ Omni-bus } & Car & 72.3363 & 309.9804 & 1.000 & -965.866 & 1110.538 \\
\hline & Trucks & 89.1500 & 787.0921 & 1.000 & -2547.018 & 2725.318 \\
\hline & Mini Bus & 2.0643 & 309.9804 & 1.000 & -1036.138 & 1040.266 \\
\hline & Motorcycle & $-2572.4286^{*}$ & 405.4144 & .000 & -3930.263 & -1214.594 \\
\hline & Tricycle & $-4301.5000^{*}$ & 594.9857 & .000 & -6294.256 & -2308.744 \\
\hline \multirow[t]{5}{*}{ Motorcycle } & Car & $2644.7649^{*}$ & 288.8680 & .000 & 1677.274 & 3612.256 \\
\hline & Trucks & $2661.5786^{*}$ & 779.0191 & .042 & 52.449 & 5270.708 \\
\hline & Mini Bus & $2574.4929^{*}$ & 288.8680 & .000 & 1607.002 & 3541.984 \\
\hline & Omni-bus & $2572.4286^{*}$ & 405.4144 & .000 & 1214.594 & 3930.263 \\
\hline & Tricycle & -1729.0714 & 584.2643 & .123 & -3685.919 & 227.776 \\
\hline \multirow[t]{5}{*}{ Tricycle } & Car & $4373.8363^{*}$ & 522.5819 & .000 & 2623.579 & 6124.094 \\
\hline & Trucks & $4390.6500^{*}$ & 892.4785 & .000 & 1401.516 & 7379.784 \\
\hline & Mini Bus & $4303.5643^{*}$ & 522.5819 & .000 & 2553.307 & 6053.822 \\
\hline & Omni-bus & $4301.5000^{*}$ & 594.9857 & .000 & 2308.744 & 6294.256 \\
\hline & Motorcycle & 1729.0714 & 584.2643 & .123 & -227.776 & 3685.919 \\
\hline \multicolumn{5}{|c|}{ *. The mean difference is significant at the 0.05 level. } & & \\
\hline
\end{tabular}

Table 3: Multiple Comparisonof Emission Differentials of HC from Automobiles Source: Field Survey, 2017 
In a nutshell, it is clear from the study that the emission levels of hydrocarbon pollutant from all the sampled automobiles were found to be higher than the standard set by the regulatory agency in the State. However, the level of concentrations was found to differ significantly according to automobile types and types of gas used to power the engines.

\section{Conclusion}

It is clear from the study that no effort should be spared towards regulating or reducing the emission levels of hydrocarbon pollutant from automobiles in Lagos State. This is due to the fact that none of the sampled automobile categories were found to emit hydrocarbon pollutant in concentrations, lower than the set standards by the regulatory authority in the State. This implies that automobile emissions undoubtedly contribute to anthropogenic pollutant emission in Lagos state through road transportation. Hence, specific steps should be taken by the State government in collaboration with the ministry of Transport and Environment to ensure a more holistic implementation and enforcements of emission regulation standards by Vehicle Inspection Officers (VIOs) which will mandate every automobile used in the State to compulsorily undergo emission test periodically before being allowed to operate in the State. In line with the above, there is the need to adopt sustainable auto-specific emission control measures with focus on the control of specific dangerous pollutant (Hydrocarbon) which is emitted by automobiles at high concentrations above the regulated limits as revealed in the study.

\section{References}

i. USEPA (1994). National Air Quality and Emission Trends Report. United State Environmental Protection Agency. Washington DC, USA.

ii. Awange, J. (2010). Motor vehicles Air Pollution in Nairobi, Kenya. Research Journal of Environmental and Earth Science, 2(4), 178-187.

iii. Wallington, T., Sullivan, J., and Hurley, M. (2008). Emissions of CO2,CO, NOX, HC, PM, HFC-134a, N20 and CH4 from the globallight duty vehicle fleet. MeteorologischeZeitschrift, 17(2), 109-116. https://doi.org/10.1127/0941-2948/2008/0275.

iv. Sprawl, J. (2001). Measuring Vehicular Contribution to Smog. Freetown, Sierra Club.

v. Wargo, J., Wargo, L., Alderman N. and Brown, D.R. (2006). The Harmful Effects of Vehicle Exhaust. A Case for Policy Change. Environmental and Human Health Inc. Retrieved May 05, 2012 from http://www.epa.gov/otaq/f02004.pdf

vi. Brunekeef, B. (2005). Out of Africa. Occupation and Environmental Medicine. 62:351- 352.

vii. Bull, K.R., (1991). The critical loads/levels approach to gaseous emission control, Environmental Pollution, 69,105-123.

viii. Barth, M. and Boriboonsomsin, K. (2008). Real-World $\mathrm{CO}_{2}$ Impacts of Traffic Congestion. Transport Research Record. Journal of the Transportation Research Board, No. 2058, Transportation Research Board, National academy of science.

ix. U.S. Global Change Research Program (USGCRP). (2005). Our Changing planet: The U.S. Climate Change Science Program for Fiscal Year 2006. Washington D.C.: U.S. Global Change Research Program. http:// http://library.globalchange.gov/products/annualreports/ our-changing-planet-the-u-s-climate-change-scienceprogram-for-fy-2006-cd (Accessed on November 1,2015).

x. Lagos State Ministry of Land and Survey, (2013). Lagos State in Map. Lagos State government.

xi. National Population Commission (NPC) (2009). The Nigeria Population Census 2006 Figures. Federal Republic of Nigeria.

xii. Taiwo, K., (2005). The Case of Lagos: Air Quality Improvement Project. A Seminar paper presented at Lagos Metropolitan Area Transport Authority (LAMATA), Lagos, Nigeria in August 2005.

xiii. World Population Review (WPR) (2015). 2015 World Population Review. Retrieved at worldpopulationreview.com/world-cities/lagos-population

xiv. Oni, S. I. (2004). Urbanization and Transportation Development in Metropolitan Lagos', in Adejugbe M. O.A (ed.) Industrialization, Urbanization and Development in Nigeria 1950 - 1999. Lagos, Concept Publications Limited.

xv. Hesterberg, T. W., Lapin, C. A. Bunn, W. B. ., (2008). A comparisonof emissions from vehicles fuelled with diesel or compressed natural gas. Environ. Sci. Technol. 42, 6437.

xvi. European Automobile Manufacturers Association/European Petroleum Industry Association, (ACEA/EUROPIA) (1995). European Programme on Emissions, Fuels, and Engine Technologies Report, Brussels.

xvii. Enviropedia, (2017). Motor Vehicle Emission Controls: Fuel Types. Retrieved on 4/19/2017 http://www.airquality.org.uk/26.php

xviii. Guensler, R., D. Sperling, and P. Jovanis. (1991). Uncertainty in the Emission Inventory for Heavy-Duty DieselPowered Trucks. UCD-ITS-RR-91-02. Institute of Transportation Studies, University of California, Davis, 146 pp

xix. Conte, F. (1990). Trucking in the '90s: Emissions. Owner Operator. Sept., pp. 58 